\title{
Epidemiology of Congenital Hypothyroidism in Markazi Province, Iran
}

\author{
Fatemeh Dorreh1, Parsa Y. Chaijan1, Javad Javaheri1, Ali Hossein Zeinalzadeh2 \\ ${ }^{1}$ Arak University of Medical Sciences, Thyroid Disorders Research Center, Department of Pediatrics, Arak, Iran \\ 2 Tabriz University of Medical Sciences, National Public Health Management Center, Department of Community Medicine, Tabriz, Iran
}

\section{ABSTRACT}

Objective: The aim of this study was to investigate the epidemiology of congenital hypothyroidism (CH) among newborns in Markazi Province, Iran.

Methods: This cross-sectional study was conducted from 2006 to 2012. Blood samples were taken between 3 to 5 days after birth from the heel. Thyroid stimulating hormone (TSH) was tested using the enzyme-linked immunosorbent assay method and was employed as the screening test. Newborns with abnormal screening results (TSH $>5 \mathrm{mlU} / \mathrm{L}$ ) were reexamined. The data were analyzed using SPSS

Results: A total of 127112 infants were screened. Of these, $51.2 \%$ were male and $48.8 \%$ were female. The coverage rate of the screening program was $100 \%$. Of 6102 recalled subjects (re-call rate $4.8 \%$ ), 414 cases with $\mathrm{CH}$ were detected, yielding a $\mathrm{CH}$ prevalence of 1:307 (female:male ratio 1:0.95). The prevalence of permanent and transient $\mathrm{CH}$ was 1:581 and 1:628, respectively.

Conclusion: This study reveals that the prevalence of $\mathrm{CH}$ is higher compared to worldwide levels. Comprehensive and complementary studies for recognizing related risk factors should be a priority for health system research in this province.

Key words: Congenital hypothyroidism, epidemiology, neonatal screening, Iran

Conflict of interest: None declared

Received: 22.01.2014

Accepted: 28.03 .2014

\section{Introduction}

Congenital hypothyroidism $(\mathrm{CH})$ is reported to affect one in 2000 to 4000 newborns, making it one of the most common causes of preventable mental retardation (1). Neonatal screening programs for $\mathrm{CH}$ allow early effective diagnosis and treatment of the condition (2). The $\mathrm{CH}$ patients may have a developmental abnormality such as thyroid gland dysgenesis or thyroid dyshormonogenesis (3). The prevalence of $\mathrm{CH}$ has been shown to vary among different populations around the world. The first screening programs for $\mathrm{CH}$ were conducted in North America in 1972 (4). Studies have suggested that the prevalence of $\mathrm{CH}$ appears to be on the increase in many countries due to many factors such as diagnosis of mild cases, increasing maternal age, increasing premature birth, multiple pregnancies and lower cut-off point $(1,5,6,7)$. In Iran, screening programs for $\mathrm{CH}$ were first carried out by Azizi et al (8) in Tehran in 1987. The first screening for $\mathrm{CH}$ in in Markazi Province was performed in 2006. According to the national screening program, the prevalence of $\mathrm{CH}$ in Iran is higher than global statistics and different prevalence figures are reported in different provinces $(5,6,9,10,11)$.

The purpose of this study was to investigate the epidemiology of $\mathrm{CH}$ among neonates screened in Markazi Province, Iran, in the years 2006-2012.

\section{Methods}

In this descriptive cross-sectional study, we used the data collected from the $\mathrm{CH}$ screening of 127112 neonates from all sources (private or public) in Markazi Province, Iran, from August 2006 to August 2012. All neonates were screened according to the standard $\mathrm{CH}$ screening protocol. In accordance with the design of the screening program, samples were collected from

\footnotetext{
Address for Correspondence

Ali Hossein Zeinalzadeh MD, Tabriz University of Medical Sciences, National Public Health Management Center, Department of Community Medicine, Tabriz, Iran Phone: +98-914-4063873 E-mail: zenalali@gmail.com

OJournal of Clinical Research in Pediatric Endocrinology, Published by Galenos Publishing.
} 
all 10 cities of the province. Heel prick blood samples were taken on 903 Whatman filter papers by trained nurses, mostly within $3-5$ days of birth. They were dried and immediately transferred to the screening laboratory of the province by express mail service. Thyroid stimulating hormone (TSH) was tested using the enzymelinked immunosorbent assay (ELISA) method.

In accordance with the national screening program protocol, neonates were re-called based on the level of the first TSH measurements. TSH $\geq 5 \mathrm{mIU} / \mathrm{L}$ in neonates aged 3-7 days and TSH $\geq 4 \mathrm{mlU} / \mathrm{L}$ in infants aged greater than eight days were considered abnormal. For such cases, additional confirmation tests [thyroxine (T4), TSH and triiodothyronine resin uptake (T3RU)] were performed. In addition, if the initial TSH level was $\geq 20 \mathrm{mlU} / \mathrm{L}$, treatment was initiated and thyroid function tests were performed concomitantly. If the results of the second set of tests were within normal limits, the neonate was considered as a case of transient TSH elevation and treatment was halted. All the re-called neonates were examined clinically by a pediatrician, a focal point of program. According to the results of the second measurement performed between 7 and 28 days of birth, neonates were considered as hypothyroid if $\mathrm{T} 4$ was $<6.5 \mu \mathrm{g} / \mathrm{dL}$ and TSH was $>10 \mathrm{mlU} / \mathrm{L}$ (12). Thus, in both premature and full-term neonates whose T4 measurements were low according to their weight (13), complementary tests including T3RU and free T4 index had been performed and treatment started if the results were abnormal. Neonates with confirmed hypothyroidism underwent treatment with a single daily dose of levo T4 (LT4) (10-15 $\mu \mathrm{g} / \mathrm{kg} /$ day). Infants diagnosed with $\mathrm{CH}$ were followed closely in the first three years of life. They were followed up monthly or every two months during the first year of life and every two to three months during the second and third years.

In order to distinguish between permanent and transient cases of $\mathrm{CH}$, LT4 therapy was discontinued for 4 weeks in children who were $\geq 3$ years old, after which time thyroid function tests ( $T 4$ and TSH) were evaluated by the same laboratory methods and the same enzymatic kits.

Thyroid scintigraphy and/or ultrasonography were performed in all patients after discontinuing treatment. If the thyroid function tests showed a high TSH with low T4, the patient was diagnosed to have permanent $\mathrm{CH}(12,13)$. The etiology of $\mathrm{CH}$ among patients with permanent $\mathrm{CH}$ was determined by both scintigraphic and ultrasonographic imaging for thyroid dysgenesis (agenesis, ectopia and hypoplasia) and thyroid function tests. Patients with abnormal thyroid function test results but normal scintigraphy and ultrasonography scans were considered to be cases of dyshormonogenesis.

Variables such as gender, residency (lodging), birth weight, maturity (full term or premature), birth season, screening sampling age, familial (maternal) history of thyroid disorder, treatment initiation age and parental consanguinity were recorded.

\section{Laboratory Methods}

TSH was measured by ELISA using Iran Padtan Elm Company kits. The sensitivity of TSH test was $0.5 \mathrm{mIU} / \mathrm{L}$. The accuracy of the TSH test was assessed using both intra- and inter-assay results.
Intra-assay coefficients of variation at TSH concentrations of 17.7, 78.4 and $162.4 \mathrm{mlU} / \mathrm{L}$ were $8.6 \%, 9.8 \%$ and $9.1 \%$, respectively. The inter-assay coefficients of variation for different methods at TSH concentrations of 15, 26.5 and $54.9 \mathrm{mIU} / \mathrm{L}$ were $11.3 \%, 9 \%$ and $8.8 \%$, respectively.

\section{Statistical Analysis}

The data were analyzed using SPSS software. Frequency, mean and standard deviation for demographic data and TSH levels in neonates were estimated. Qualitative variables were compared using the chi-square test and quantitative/qualitative variables were compared by t-test and Kruskal-Wallis tests. All p-values were twosided with $p<0.05$ being considered significant. The Medical Ethics Committee of Arak University of Medical Sciences approved the study protocol.

\section{Results}

During the study period, 127112 neonates were screened. Of the screened newborns, 65090 (51.2\%) were male and 62022 $(48.8 \%)$ were female. The female:male ratio was 1.00/0.95. Except for year 2006 , approximately $100 \%$ of all neonates in the population were screened. In $79.9 \%$ of neonates, the samples were taken 3-5 days after birth. In $18.9 \%$ of the neonates, the samples were taken between 5 and 21 days and in $1.1 \%$ - later than 21 days after birth.

The distribution of serum TSH values among the hypothyroid neonates is shown in Table 1. The mean TSH level in all measured samples was $19.1 \pm 29.1 \mathrm{mlU} / \mathrm{L}$. The distribution of TSH levels showed that 372 (89\%) of 414 diagnosed $\mathrm{CH}$ neonates had initial TSH values over $5 \mathrm{mIU} / \mathrm{L}$. In addition, 215 (52\%) had TSH values between 4.5 and $9.9 \mathrm{mlU} / \mathrm{L}$. In accordance with the national guidelines, these neonates were re-called for additional confirmatory testing. Overall, 6102 neonates (4.8\%) were recalled. Of these, 414 (6.8\%) were diagnosed as $\mathrm{CH}$ cases. The prevalence of $\mathrm{CH}$ among all subjects studied was 3.25/1000 or 1:307 live births. Among neonates with $\mathrm{CH}, 212$ (51.2\%) were male and 202 (48.8\%) were female (male: female ratio 1.05:1). The prevalence of $\mathrm{CH}$ among male and female neonates was $3.15 / 1000$ and 3.25/1000, respectively. Chi-square test showed no statistically significant relation between gender and $\mathrm{CH}(\mathrm{p}=0.236)$. The mean birth weight of the total group of $\mathrm{CH}$ neonates was $3047 \pm 60 \mathrm{~g}$. This figure was $3188 \pm 23$ and $1905 \pm 75$ grams for term and preterm $\mathrm{CH}$ neonates, respectively. There was no statistically significant difference between mean birth weight of neonates and hypothyroid subjects ( $p=0.34)$. Of the $\mathrm{CH}$ cases, 360 (89.1\%) were full-term and 44 (10.9\%) were premature. There was no statistically significant difference between maturity and hypothyroidism $(\mathrm{p}=0.13)$. In 22 of $\mathrm{CH}$ neonates $(5.3 \%, 22 / 414)$, the mother had a history of thyroid disease. Also, in $58(14 \%, 58 / 414)$ cases, there was a family history of thyroid disease. There was a statistically significant relation between family history of thyroid diseases and hypothyroidism ( $\mathrm{p}=0.037)$. Parental consanguinity was present in $26 \%(105 / 414)$ of all $\mathrm{CH}$ cases. In $76(18.5 \%)$ cases, parents had third-cousin consanguinity and in $29(7 \%)$, there was fourth 
-cousin consanguinity between parents. There was no statistically significant difference between parental consanguinity and hypothyroidism ( $p=0.456)$.

The frequency of $\mathrm{CH}$ varied according to season. The highest prevalence of $\mathrm{CH}$ was in autumn, but there was no relation between $\mathrm{CH}$ and season because this difference was not statistically significant $(p=0.094)$.

\begin{tabular}{|lcc|}
\hline \multicolumn{2}{|l|}{ Table 1. Distribution of thyroid stimulating hormone (TSH) levels among } \\
hypothyroid neonates, on their first measurement \\
\hline Distribution of TSH levels (mIU/L) & $n$ & $\%$ \\
\hline $0-4.9$ & 42 & 10.1 \\
\hline $5-9.9$ & 215 & 51.9 \\
\hline $10-19.9$ & 77 & 18.7 \\
\hline$\geq 20$ & 80 & 19.3 \\
\hline Total & 414 & 100 \\
\hline
\end{tabular}

Table 2 shows the characteristics of neonates with permanent and transient $\mathrm{CH}$. Of 414 patients diagnosed with hypothyroidism, a diagnostic discontinuation of therapy at around three years was undertaken in 235; in these 235 patients, treatment was discontinued for 4 weeks and their T4 and TSH were measured again. Of these, 122 (51.9\%) were found to have permanent $\mathrm{CH}$. The remaining $113(48.1 \%)$ were diagnosed as transient $\mathrm{CH}$. Of 127112 screened neonates, 71019 had reached 3 years or more and in this group, the prevalence of permanent and transient $\mathrm{CH}$ was found as 1:581 (1.72/1000) and 1:628 (1.59/1000) live births, respectively. Of the $\mathrm{CH}$ neonates, sonography was performed in 7 and all were assessed as normal (2 cases of transient $\mathrm{CH}$ and 5 cases of permanent $\mathrm{CH}$ ). Thyroid scintigraphy was performed in $26 \%(61 / 235)$ of hypothyroid neonates. According to scintigraphic findings performed in 43 permanent and 18 transient hypothyroid neonates, all transient $\mathrm{CH}$ patients had normal thyroid glands and in permanent $\mathrm{CH}$ patients, $5(2.1 \%)$ had thyroid dysgenesis (2 agenesis or hypoplasia and 3 ectopia) and 6 (2.55\%) had dyshormonogenesis. Overall, in $50(21.3 \%)$ neonates, the thyroid scan was normal.

Table 2. Univariate analysis of characteristics of the neonates with permanent and transient $\mathrm{CH}$

\begin{tabular}{|c|c|c|c|c|}
\hline Variables & & $\begin{array}{c}\text { Permanent CH } \\
\text { No }(\%) / \text { mean } \pm \text { SD }\end{array}$ & $\begin{array}{c}\text { Transient CH } \\
\text { No }(\%) / \text { mean } \pm \text { SD }\end{array}$ & $\mathrm{p}$-value \\
\hline \multirow{2}{*}{ Gender } & Male & $58(47.5)$ & $60(53.1)$ & \multirow{2}{*}{0.236} \\
\hline & Female & $64(52.5)$ & $53(46.9)$ & \\
\hline Birth Weight (g) & & $3157 \pm 464$ & $3029 \pm 625$ & 0.080 \\
\hline \multirow{2}{*}{ Maturity } & Term & $115(95.8)$ & $100(89.5)$ & \multirow{2}{*}{$0.48 *$} \\
\hline & Preterm & $5(4.2)$ & $53(46.9)$ & \\
\hline \multirow{2}{*}{ Parental consanguinity } & Absent & $89(74.2)$ & $85(76.6)$ & \multirow{2}{*}{0.388} \\
\hline & Present & $31(25.9)$ & $26(23.4)$ & \\
\hline Age at start of treatment (day) & & $21.7 \pm 12.52$ & $25.43 \pm 11.54$ & $0.01^{*}$ \\
\hline LT4 dose (total daily dose) & & $30.93 \pm 13.25$ & $31.04 \pm 12.46$ & 0.817 \\
\hline TSH level at first measurement (mIU/L) & & $32.31 \pm 40.25$ & $11.94 \pm 16.4$ & $0.0001^{*}$ \\
\hline \multirow{4}{*}{ Season } & Spring & $28(23)$ & $27(23.9)$ & \multirow{4}{*}{0.065} \\
\hline & Summer & $27(22.1)$ & $29(25.7)$ & \\
\hline & Autumn & $46(37.7)$ & $26(23)$ & \\
\hline & Winter & $21(17.2)$ & $31(27.4)$ & \\
\hline \multirow{2}{*}{ Residency } & Urban & $73(59.8)$ & $65(57.5)$ & \multirow{2}{*}{0.410} \\
\hline & Rural & $49(40.2)$ & $48(42.5)$ & \\
\hline \multirow{2}{*}{ Kind of delivery } & Normal vaginal delivery & $79(65.8)$ & $87(79.1)$ & \multirow{2}{*}{$0.018^{*}$} \\
\hline & Cesarean section & $41(34.2)$ & $23(29.9)$ & \\
\hline \multirow{2}{*}{ Family history of $\mathrm{CH}$} & Absent & $101(84.2)$ & $103(92.8)$ & \multirow{2}{*}{$0.032^{*}$} \\
\hline & Present & $19(15.8)$ & $8(7.2)$ & \\
\hline
\end{tabular}




\section{Discussion}

The prevalence of $\mathrm{CH}$ among neonates in Markazi Province of Iran has not previously been determined, but this study shows that the estimated prevalence is one in 307 live births. This is approximately 6.5 to 13 -fold of figures reported from other countries (1). With more experience from state, regional and national screening programs, it has become apparent that the prevalence of $\mathrm{CH}$ varies throughout the world, but the worldwide reported prevalence is one in 2000-4000 live births $(1,14)$. According to recent data, this prevalence has been reported as 1:469 in Turkey (15), 1:800 in Greek Cypriot populations (16) and 1:2372 in the United States (17). There are a few pilot studies on the prevalence of $\mathrm{CH}$ conducted in Iran prior to the National Screening Program. Ordookhani et al (18) reported that the prevalence of $\mathrm{CH}$ in Tehran (Iran's capital) was 1:914 in 20107 newborns screened between 1987 and 2001. The estimated prevalence in our study was significantly higher than that found in the previous studies (1 in 1465, 1 in 500 and 1 in 666 live births in Fars, the eastern and northwestern parts of Iran, respectively) $(9,11)$.

Differences in the prevalence of $\mathrm{CH}$ reported from different parts of the world may be due to several factors. The studies have reported a high $\mathrm{CH}$ prevalence in Iran. lodine deficiency is a known risk factor for $\mathrm{CH}$ (8). The wide variability of $\mathrm{CH}$ prevalence with the same methodology in different parts of the same country may reflect the degree of iodine deficiency in each region, but this problem has been eradicated in Iran (19). However, there may be factors other than iodine deficiency affecting $\mathrm{CH}$ incidence in different regions. The differences in incidence may be due to differences in ethnic, environmental, genetic and autoimmune factors $(20,21,22,23)$. Thus comprehensive, complementary and multicenter studies for recognizing the relevant factors affecting the prevalence of $\mathrm{CH}$ are among the priorities of the health system research in Iran.

$\mathrm{CH}$ re-call rates also vary (from $0.16 \%$ to $3.3 \%$ ) among different countries in which the screening programs were performed between 3 and 5 days after birth $(24,25,26)$. In the present study, the recall rate was $4.8 \%$, which was a comparatively higher figure. The difference can be due to the sampling method, a different way of performing laboratory tests, or may be a reflection of the degree of iodine deficiency in each region $(25,27)$. However, this study was preliminary and further studies are needed to clarify the causes of these differences.

According to the American Academy of Pediatrics recommendations, the optimal testing time is between 48 hours and 4 days of birth. The national $\mathrm{CH}$ screening programs in Iran aim to test neonates between three and five days of life. However, the data indicate that not all, but approximately $80 \%$ of the samples in our study were taken between the third and fifth days of life. Age at the start of treatment has been demonstrated to be an important determinant of neurodevelopmental outcome and early newborn screening and early treatment with T4 may prevent the adverse neurodevelopmental consequences of delayed diagnosis and treatment $(28,29)$. However, in most countries, treatment is now started earlier, usually being initiated within the first 2 weeks of life $(30,31)$. In our study, mean age of initiation of treatment was $22.7 \pm 11$ days. We hope that over the years, there will be a trend for earlier start of treatment.

The female:male ratio for $\mathrm{CH}$ varies in different countries and is reported as 6:1 in Estonia, 3:1 in Saudi Arabia, 1.2:1 in Japan and as $1.4: 1$ in the eastern part of Iran $(15,32,33,34)$. Results of nearly all screening programs also suggest a female preponderance for $\mathrm{CH}$, approaching a 2:1 female to male ratio (1). In the present study, this ratio was 1:0.95. Recently, Zeinalzadeh and Talebi reported the results of screening for $\mathrm{CH}$ in 62459 infants in East Azerbaijan, Iran. Female/male ratio was 1:1.4 (11). The differences in prevalence and in female/male ratios may be due to differences in prevalence of consanguineous marriages and to differences in frequency of undiagnosed family history of $\mathrm{CH}$, as reported also by Castanet et al (20). Again, the preponderance of $\mathrm{CH}$ in females might be due to undiscovered genetic factors, perhaps linked to autoimmuity, which is usually more common in females (1). In 22 of the $\mathrm{CH}$ neonates in our study (5.3\%), the mother also had a history of thyroid disease, supporting the importance of genetic factors as a possible cause of $\mathrm{CH}$ (16).

Seasonal variation in $\mathrm{CH}$ incidence has been reported in some studies $(3,11,15)$. These studies have suggested that the causes of $\mathrm{CH}$ are not only intrinsic factors such as immune system dysfunction or gene defects, but environmental factors also play a role. Moreover, there was some speculation as to a possible seasonal variation in the incidence of $\mathrm{CH}$. In our study, the highest prevalence was found in autumn and the lowest prevalence in spring. However, we agree that these results are not conclusive and that this topic is still under debate $(1,34)$.

Studies suggest that children with transient $\mathrm{CH}$ require a lower dose of $\mathrm{T} 4$ in order to maintain normal thyroid hormone levels than those with permanent $\mathrm{CH}$ (16). These findings are not in agreement with the results from our study because there was no statistically significant difference between the two groups. However, mean TSH levels before treatment were significantly higher in the patients with permanent $\mathrm{CH}$ than in those with transient $\mathrm{CH}$. This finding indicates that the initial TSH level obtained at screening may have a predictive role for identifying the permanent forms of $\mathrm{CH}$ from the transient ones. The results of a study performed in Brazil by Silva et al (35) to assess the characteristics and etiologies of transient $\mathrm{CH}$, the TSH initial levels were reported not to be relevant to determine whether the thyroid dysfunction was transient or permanent. In our study, the prevalence of permanent $\mathrm{CH}$ was high with a prevalence rate of 1 in 581 live births. The prevalence of transient $\mathrm{CH}$ was 1 in 628 live births. Prevalence of permanent $\mathrm{CH}$ was reported to be 1 in 2679 in Quebec-Canada, 1 in 2418 in China and 1 in 1800 in Greece $(16,36,37)$. The higher prevalence of $\mathrm{CH}$ in Arak was due to a higher rate of permanent $\mathrm{CH}$, whereas in other studies from Iran, the rate of transient $\mathrm{CH}$ is higher than that of permanent $\mathrm{CH}$. These differences may be due to differences in screening method 
or to differences in environmental or immunologic factors. To our knowledge, there have been no systematic studies in these fields among newborns with transient versus permanent hypothyroidism in Arak.

In the present study, parental consanguinity was found in $19(15.8 \%)$ and $8(7.2 \%)$ cases of permanent and transient $\mathrm{CH}$, respectively, indicating that parental consanguinity was 2.2 times more frequent in cases of permanent $\mathrm{CH}$ compared to neonates with transient $\mathrm{CH}$. Other studies in Iran have also shown that parental consanguinity is higher in cases of $\mathrm{CH}$ than among neonates without $\mathrm{CH}$ (38). Further investigations are needed to evaluate the role of parental consanguinity and its effect on the incidence of $\mathrm{CH}$ and whether it has a greater effect on the incidence of permanent versus transient $\mathrm{CH}$.

In conclusion, the results of this study reveal that the prevalence of $\mathrm{CH}$ is higher in the Markazi Province of Iran than the figures reported from other parts of the world. The study also shows the need to integrate proper screening programs for $\mathrm{CH}$ and also to initiate programs to evaluate the related risk factors in the routine healthcare system in this province.

\section{Acknowledgements}

Our study was funded by the Thyroid Research Center of Arak University of Medical Sciences \& Health Services. There is no conflict of interest in this manuscript (real or perceived) and there was no study sponsor(s) in all process of the study.

\section{References}

1. Rastogi M, Lafranchi S. Congenital hypothyroidism OJRD 2010:5:17-22

2. Cao XY, Jiang XM, Dou ZH, Rakeman MA, Zhang ML, O'Donnell $\mathrm{K}, \mathrm{Ma}$, Amette K, DeLong N, DeLong GR. Timing of vulnerability of the brain to iodine deficiency in endemic cretinism. N Engl $J$ Med 1994;331:1739-1744.

3. Hashemipour M, Amini M, Kelishadi R, Hovsepian S, Haghighi S, Hosseini M, Talaei M. Seasonal variation in the incidence of congenital hypothyroidism in Isfahan, Iran. Saudi Med J 2007;28:1582-1586.

4. Klett M. Epidemiology of congenital hypothyroidism. Exp Clin Endocrinol Diabetes 1997;105(Suppl 4):19-23.

5. Dalili S, Rezvany SM, Dadashi A, Medghalchi A, Mohammadi $H$, Dalili H, Mirzanejad M, Gholamnezhad H, Amirhakimi A. Congenital hypothyroidism: a review of the risk factors. Acta Med Iran 2012;507:735-739.

6. Hashemipour M, Hovsepian S, Kelishadi R.High prevalence of congenital hypothyroidism in Isfahan: Do familial components have a role? Adv Biomed Res 2012;1:37. Epub 2012 Aug 28

7. Ordookhani A, Padyab M, Goldasteh A, Mirmiran P, Richter J, Azizi $F$. Seasonal variation of hypothyroidism and recall rate in neonates. IJEM 2003;16:247-243.

8. Azizi F, Oladi B, Nafarabadi MT, Hajipoor R. Screening for congenital hypothyroidism in Tehran: Effect of iodine deficiency on transient elevation of neonatal TSH. J Shaheed Beheshti School Med 1994;18:34-8.

9. Karimi Zadeh Z, Saneifard H, Amir Hakimi GH, Karamifar H, Alavi M. Evaluation of congenital Hypothyroidism in fars province, Iran. Iran J Peditr 2012;22:107-112.
10. Najafi M, Khodaee GH, Bahari M, Sabahi M, Farsi MM, Kiani F. Neonatal thyroid screening in a mild iodine deficiency endemic area in Iran. Indian J Med Sci 2008;62:113-116.

11. Zeinalzadeh $A H$, Talebi M. Neonatal screening for congenital hypothyroidism in East Azerbaijan, Iran: the first report. J Med Screen 2012;19:123-126. Epub 2012 Oct 11

12. Fisher DA. Physiological variations in thyroid hormones: Physiological and pathophysiological considerations. Clin Chem 1996;42:135-139.

13. Frank JE, Faix JE, Hermos RJ, Mullaney DM, Rojan DA, Mitchell ML, Klein RZ. Thyroid function in very low birth weight infants: effects on neonatal hypothyroidism screening. J Pediatr 1996;128:548-554.

14. Roberts HE, Moore CA, Fernhoff PM, Brown AL, Khoury MJ.Population study of congenital hypothyroidism and associated birth defects, Atlanta, 1979-1992. Am J Med Genet 1997;71:29-32.

15. Dilli $D$, Çzbaş $S$, Acıcan D, Yamak N, Ertek M, Dilmen U. Establishment and development of a national newborn screening programme for congenital hypothyroidism in Turkey. J Clin Res Pediatr Endocrinol 2013;5:73-79.

16. Skordis N, Toumba M, Savva SC, Erakleous E, Topouzi M, Vogazianos $M$, Argyriou A. High prevalence of congenital hypothyroidism in the Greek Cypriot population: results of the neonatal screening program 1990- 2000. J Pediatr Endocrinol Metab 2005;18:453-461.

17. Harris KB, Pass KA. Increase in congenital hypothyroidism in New York State and in the United States. Mol Genet Metab 2007;91:268-277. Epub 2007 May 23

18. Ordookhani A, Mirmiran P, Hedayati M, Hajipour R, Azizi F. Screening for congenital hypothyroidism in Tehran and Damavand: An interim report on descriptive and etiologic findings, 1998-2001. IJEM 2002;4:153-160.

19. Azizi F, Sheikholeslam R, Hedayati M, Mirmiran P, Malekafzali H, Kimiagar M, Pajouhi M. Sustainable control of iodine deficiency in Iran: Beneficial results of the implementation of the mandatory law on salt iodization. J Endocrinol Invest 2002;25:409-413.

20. Castanet M, Polak M, Bonaïti-Pellié C, Lyonnet S, Czernichow P, Léger J; AFDPHE (Association Française pour le Dépistage et la Prévention des Handicaps de I'Enfant). Nineteen years of national screening for congenital hypothyroidism: familial cases with thyroid dysgenesis suggest the involvement of genetic factors. J Clin Endocrinol Metab 2001;86:2009-2014.

21. Ordookhani A, Pearce EN, Mirmiran P, Azizi F, Braverman LE. Transient congenital hypothyroidism in an iodine-replete area is not related to parental consanguinity, mode of delivery, goitrogens, iodine exposure, or thyrotropin receptor autoantibodies. J Endocrinol Invest 2008;31:29-34.

22. Benvenga S, Ordookhani A, Pearce EN, Tonacchera M, Azizi F, Braverman LE. Detection of circulating autoantibodies against thyroid hormones in an infant with permanent congenital hypothyroidism and her twin with transient congenital hypothyroidism: possible contribution of thyroid hormone autoantibodies to neonatal and infant hypothyroidism. J Pediatr Endocrinol Metab 2008;21:1011-1020.

23. Rivolta CM, Moya CM, Esperante SA, Gutnisky VJ, Varela V, Targovnik HM. The thyroid as a model for molecular mechanisms in genetic diseases. Medicina (B Aires) 2005;65:257-267.

24. Fagela-Domingo $C$, Padilla CD, Cutiongco EM. Screening for congenital hypothyroidism among Philippine newborn infants. Philippine newborn screening study group. Southeast Asian J Trop Med Public Health 1999;30(Suppl 2):20-22.

25. Simsek E, Karabay M, Kocabay K. Neonatal screening for congenital hypothyroidism in West Black Sea area, Turkey. Int J Clin Pract 2005;59:336-341. 
26. Mikelsaar RV, Zordania R, Viikmaa M, Kudrjavtseva G. Neonatal screening for congenital hypothyroidism in Estonia. J Med Screen 1998;5:20-21.

27. Hashemipour M, Amini M, Iranpour R, Sadri GH, Javaheri $N$, Haghighi $S$, et al. Prevalence of congenital hypothyroidism in Isaac, Iran: Results of a survey on 20000 neonates. Horm Res 2004;62:79-83.

28. Tillotson SL, Fuggle PW, Smith I, Ades AE, Grant DB. Relation between biochemical severity and intelligence in early treated congenital hypothyroidism: a threshold effect. BMJ 1994;309:440-445.

29. Klein $\mathrm{AH}$, Meltzer $\mathrm{S}$, Kenny FM. Improved prognosis in congenital hypothyroidism treated before age three months. J Pediatr 1972;81:912-915.

30. Jain V, Agarwal R, Deorari AK, Paul VK. Congenital hypothyroidism. Indian J Pediatr 2008;75:363-367.

31. Rose SR, Brown RS. Update of newborn screening and therapy for congenital hypothyroidism. Pediatrics 2006;117:2290-2303.

32. Olney RS, Grosse SD, Vogt RF Jr. Prevalence of congenital hypothyroidism-current trends and future directions: workshop summary. Pediatrics 2010;125(Suppl 2):31-36.

33. Al-Maghamsi MS, Al-Hawsawi ZM, Ghulam GN, Okasha AM. Screening for congenital hypothyroidism in north-west region of Saudi Arabia. Saudi Med J 2002;23:1518-1521.
34. Miyai K, Inaoka K, Miyagi T; Committee for Newborn and Infant Screening in Osaka (CONISO). Further studies on episodic occurrence of congenital dysgenetic hypothyroidism in Osaka, Japan. Endocr J 2005;52:599-603.

35. Silva LO, Dias VM, Silva IN, Chagas AJ. Congenital transient hypothyroidism: characteristics of children identified at Newborn Screening Program of the State of Minas Gerais, Brazil. Arq Bras Endocrinol Metabol 2005;49:521-528. Epub 2005 Oct 19

36. Deladoëy J, Ruel J, Giguère Y, Van Vliet G. Is the incidence of congenital hypothyroidism really increasing? A 20 year retrospective population based study in Québec. J Clin Endocrinol Metab 2011;96:2422-2429. Epub 2011 Jun 1

37. Sun $Q$, Chen YL, Yu ZB, Han SP, Dong XY, Qiu YF, Sha L, Guo $X R$. Long term consequences of the early treatment of children with congenital hypothyroidism detected by neonatal screening in Nanjing, China: A 12 year follow up study. J Trop Pediatr 2012;58:79-80. Epub 2011 Feb 4

38. Ordookhani A, Mirmiran P, Moharamzadeh M, Hedayati M, Azizi F. A high prevalence of consanguineous and severe congenital hypothyroidism in an Iranian population. J Pediatr Endocrinol Metab 2004;17:1201-1209. 